\title{
The Importance of a Complete Clinical History: The Vision of the Patient as a Whole
}

\author{
V García Paz*, Fernández Rodríguez M, Meijide Calderón A, Carballeira Anca I and Castro Murga M \\ Allergy Department, Spain
}

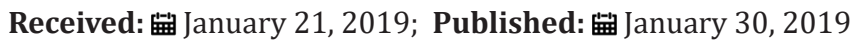

*Corresponding author: Vanesa García Paz, Allergy Department, A Coruña, Spain

\begin{abstract}
Summary
The medical history is the most important scientific, technical and legal document that is part of the daily work of the doctor. In it, the greatest possible number of data must be collected in order to arrive at a scientific opinion, the clinical judgment. A complete anamnesis is important, seeing the patient in an integral way, to arrive at the correct diagnosis and to be able to carry out the most appropriate therapeutic measures. In an increasingly specialized medicine, the medical specialties that see the patient in an integral way, are still necessary.
\end{abstract}

keywords: Medical History; Asthma; Severe Asthma; Allergy; Egg; Aspergillosis

\section{Introduction}

The Clinical History is the document that constitutes the set of information related to the care processes of each patient, written for their benefit and that should integrate the maximum information of the same. It is possibly the most important scientific, technical and legal document carried out by the doctor [1,2]. It also constitutes the essential document of learning in clinical practice, which is almost as old as humanity itself. It is born as the elementary document of medical experience, having evolved, as technologies and scientific advances do, from its origin with papyrus to twenty-five centuries later to electronic format. There was, there is and will be a need for physicians to record in writing everything that happens in the care process $[1,2]$. It has 4 main characteristics:

a. Professionalism: Only the medical professional can develop a good clinical history.

b. The execution: It is exercised according to the standards of excellence of the moment.

c. The objective: To help the patient that translates into what is transcribed in the story.

d. The lawfulness: It is due to the legal norm that supports the clinical history as an indispensable document.

In it must be recorded the steps taken to reach that scientific opinion. Hence the importance of its completeness, to frame the largest number of data in an orderly manner and reach valid conclusions [4]. Since it contains private information it must guarantee the privacy of the patient, is subject to the law of data protection and professional secrecy; it must be elaborated with the purpose of protecting and preserving the health of the patient, but it can also be used for research and teaching. Understanding in this way, also by the laws, the necessity of the patient's individual history as a scientific method for the development and learning of medicine. Since we can consider each patient as the subject of their own research, the preparation of a good detailed and exhaustive clinical history is essential to reach a correct diagnosis and treatment.

\section{Clinical Case}

In this context, we present the case of a 56-year-old woman with remarkable personal history of hypothyroidism secondary to thyroidectomy due to goiter, epilepsy, pulmonary tuberculosis in childhood, bronchial asthma for 20 years and currently diagnosed with severe asthma with bronchiectasis and colonization by Pseudomona Aeruginosa, followed in a pulmonology clinic. As a chronic treatment the patient carries: Omeprazole, Salbutamol, Carbamazepine, Montelukast, Relvar Ellipta (fluticasone furoate / vilanterol), Atrovent (Ipratropio), Theo Dur (theophylline), Incruse (Umeclidinium bromide), Sertraline, Diazepam, Budesonide nasal spray. She is referred to the allergy consultation because she has had an immediate pharyngeal pruritus and abdominal pain for 1 year with egg. It started happening with a little egg made as a fried egg or omelet and later with a very cooked egg as a boiled egg. Currently tolerates baked, egg-baked foods: cookies, biscuits, muffins etc. The rest of the egg forms do not tolerate them. She refers in the last 6 months, when she cleans and manipulates the 
raw chicken meat to cook it, she immediately presents cutaneous injuries, welts, in her hands which disappear when she washes them, in half an hour-1 hour, she does not wear gloves. It does not associate other symptoms. She tolerates cooked chicken ingestion.

Due to the low frequency of food allergy to eggs as an adult debut, we consider the possibility that there is an atopic background in this patient that can explain their allergic pathology. Thus, a complete allergological anamnesis is performed. It presents persistent nasal and ocular symptoms such as nasal congestion, rhinorrhea, sneezing, ocular pruritus, at any time of the year without improvement in summer. She uses antihistamine and nasal budesonide on demand. She refers to night sweating that has soaked the bed for about 1 year, weight loss of $6 \mathrm{~kg}$ in the last 6 months and worsening of his bronchial pathology with more dyspnoea and recurrent respiratory infection income. We ask about the habitat, he lives in an urban area, in an apartment with fish, a dog and a canary, there is no humidity in this house.
Insisting on the existence of birds, she says that there were always birds in his house, parakeets and that he had a parrot. I check in her electronic medical history a positive sputum culture for the summer of 2017 for Penicillium fungus. On physical examination the skin is normal, pulmonary auscultation: diminished vesicular murmur and anterior rhinoscopy congestive mucosa with mild watery rhinorrhea. Weight 47 kilograms. We suspect that she is an atopic patient diagnosed with asthma approximately 20 years ago and she associates symptoms of rhino conjunctivitis. She was never studied whether the cause of asthma was allergic or not and now she has symptoms of food allergy to egg. If we try to see the patient in an integral way, without separating her respiratory pathology from her food allergy symptoms, we can see a common link in all those symptoms that a priori seem to have nothing in common. To begin with, we suspect a bird-egg syndrome and we also try to explain the worsening of its respiratory pathology in recent times. The complementary explorations were done and are detailed in the following Table 1.

Table 1: The complementary explorations.

\begin{tabular}{|c|c|}
\hline \multicolumn{2}{|r|}{ The complementary explorations } \\
\hline $\begin{array}{l}\text { Prick test prick test with habitual } \\
\text { inhalants from our environment: }\end{array}$ & $\begin{array}{l}\text { Positive Aspergillus Fumigatus and Alternaria alternata. } \\
\text { Negative dust mites, grass pollen, trees, cat, dog and panallergens profilin, polcalcine and LTP (lipid transport } \\
\text { protein). }\end{array}$ \\
\hline $\begin{array}{l}\text { Prick test with egg and egg } \\
\text { proteins: }\end{array}$ & $\begin{array}{l}\text { Positive whole egg, egg white, yolk, ovalbumin } \\
\text { Negative Ovomucoid }\end{array}$ \\
\hline $\begin{array}{l}\text { Prick test with commercial extract } \\
\text { chicken, chicken feathers, feathers } \\
\qquad \text { mix: }\end{array}$ & $\begin{array}{l}\text { Positive feathers mix, chicken feathers. } \\
\text { Negative chicken. }\end{array}$ \\
\hline $\begin{array}{l}\text { Prick by prick with raw chicken } \\
\text { meat and cooked chicken meat }\end{array}$ & Positive raw chicken meat \\
\hline ESPRINT Questionary & 4.14 points moderate-severe rhinoconjunctivitis ) \\
\hline ACT (Asthma Control Test) & 5 points \\
\hline $\begin{array}{l}\text { Forced Basal Spirometry (Spi- } \\
\text { rometer Datospir } 600 \text { Touch tool, } \\
\text { software from SILBEMED e-20 } \\
\text { Roselló, } 08026 \text { Barcelona, Spain). }\end{array}$ & FVC 59\%, FEV1 35\%, FEV1/FVC 57\%. Bronchodilation not significant \\
\hline September 2018 sputum culture & $\begin{array}{c}\text { Pseudomonas aeruginosa (1) sensitive to ceftacidime, colistin, piperacillin-tazobactam and tobramicyn; resistan to } \\
\text { ciprofloxacin }\end{array}$ \\
\hline October 2018 sputum culture & aspergillus fumigatus y aspergillus niger \\
\hline August 2018 Blood Test & 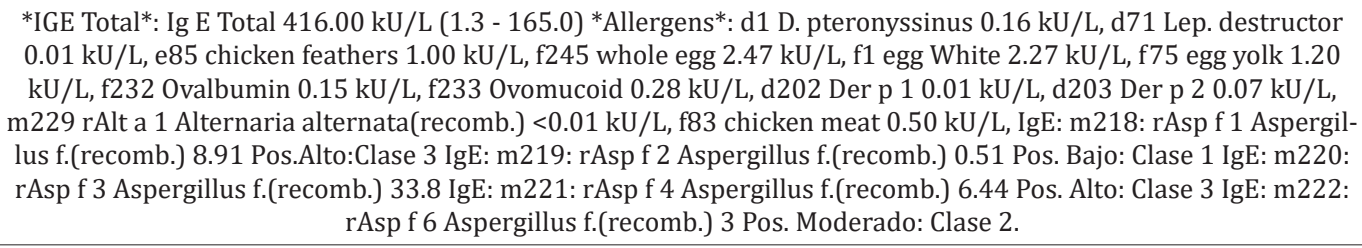 \\
\hline September 2018 Blood Test & $\begin{array}{c}\text { * Total IGE *: Ig E Total } 607.00 \mathrm{kU} / \mathrm{L}(1.3 \text { - 165.0) * Allergens *: m1 Penicillium notatum } 5.44 \mathrm{kU} / \mathrm{L}, \text { Precipi- } \\
\text { tins:p949 Aspergillus fumigatus POSITIVE Method: Immuno double diffusion (Ouchterlony technique). IgE: f323: } \\
\text { Conalbumin0.1 Negative: Class 0 IgE: k208: Lysozyme 1.31 Moderate Pos .: Class 2, Precipitins: p950 Aspergillus } \\
\text { niger NEGATIVE }\end{array}$ \\
\hline
\end{tabular}

Cite this article: V García Paz, Fernández Rodríguez M, Meijide Calderón A, Carballeira Anca I, Castro Murga M. The Importance of a Complete Clinical History: The Vision of the Patient as a Whole. Biomed J Sci \& Tech Res 13(5)-2019. BJSTR. MS.ID.002461. DOI: 10.26717/ BJSTR.2019.13.002461. 


\begin{tabular}{|c|c|}
\hline $\begin{array}{l}\text { October } 2018 \text { Computed Tomog- } \\
\text { raphy Scan of the Chest }\end{array}$ & $\begin{array}{l}\text { - Central and peripheral bronchiectasis of diffuse distribution in all lobes, with thickened walls. } \\
\text {-Pulmonary millimeter nodules of tree distribution in bud, predominantly in the right lower lobe. } \\
\text { - Subsegmental atelectasis in the anterior segment of the lower lobe of the right lung. } \\
\text { - Mosaic perfusion lung pattern in relation to the presence of areas with air trapping. } \\
\text { - Loss of volume of the upper lobe of the left lung, with lesions of fibrocicatric aspect. } \\
\text { - Multiple nodules / calcified lung masses, probably related to granulomas. Incidentally, splenic granulomas are } \\
\text { also visualized. } \\
\text { - Multiple mediastinal adenopathies, bilateral pulmonary hilar and intra and retroperitoneal calcified. } \\
\text { CONCLUSIONS Findings compatible with the clinical suspicion of allergic bronchopulmonary aspergillosis. Find- } \\
\text { ings suggestive of remote granulomatous process. }\end{array}$ \\
\hline ISAC Test & POSITIVE GALD5 \\
\hline
\end{tabular}

\section{Discussion}

The results of the tests performed on the patient confirm persistent moderate-severe rhino conjunctivitis and severe bronchial asthma with bronchiectasis. In addition, the clinical history and studies conducted lead to a bird-egg syndrome $[5,6]$ : Diagnosed of asthma for about 20 years, in the context of respiratory allergy to feathers of the birds that she had as pets. In the evolution of their basic allergic pathology, food allergy to eggs, contact urticaria to raw chicken [7] and ABPA (Allergic Bronchopulmonary Aspergillosis) have appeared [8,9]. It meets criteria for ABPA (diagnosis of asthma, positive IgE for Aspergillus, elevation of total IgE, serum precipitins against Aspergillus, bronchiectasis) which aggravates its bronchial respiratory pathology $[10,11]$. The diagnosis of this patient would not have been possible without a detailed anamnesis and looking for a common origin in all the symptoms and signs of the patient. It is possible that, if a correct diagnosis of asthma had been made from the beginning, of an allergic cause, with elimination of the house birds in addition to the medical treatment of asthma with inhaled bronchodilators and corticosteroids, the evolution of the patient would have been different. In these times in which modern medicine is so specialized and parceled, it is necessary to remember the need to see the patient as a whole in order to arrive at more precise diagnoses. We can say that, the specialties that see the patient in an integral way, still have a place.

\section{Conclusion}

With the birth of the Clinical History, the elementary document of medical experience is born, which also represents the fundamental document of medical knowledge. In an increasingly specialized and parceled medicine, integrative specialties, such as Allergology in this case, are necessary, since it is characterized as a multidisciplinary specialty, which shares fields of knowledge with other specialties with which it maintains close contact (Pulmonology, Internal Medicine, Pediatrics, Dermatology, Immunology, Digestive Medicine, Otorhinolaryngology, Ophthalmology), but unlike some of them, it does not focus on a single organ, apparatus or system, but considers the patient as a whole. The specialist allergist acts with an integrating perspective of all these pathologies with a common mechanism, which allows him to be unique in the comprehensive evaluation of the allergic patient. Although in today's medicine we have reached a great complexity in documents and complementary tests, the record of our observation of the patient continues being the method that turns our art into science. The authors declare that we have no conflicts of interest

\section{References}

1. Law $41 / 2002$, of November 14 , basic regulatory of the autonomy of the patient and of rights and obligations in matter of information and clinical documentation.

2. Galán Cáceres, Juan Calixto (2014) Medicine and legal responsibility. Medicine and Law, two worlds in convergence $\left(1^{\text {st }}\right.$ edn).

3. Fombella Posada MJ, Cereijo Quinteiro MJ (2012) History of the clinical history. Galicia Clin 73(1): 21-26.

4. Guzmán F (1999) The clinical history: Fundamental element of the medical act. Colombian Journal of Plastic Surgery 5: 115-25.

5. Inomata N, Kawano K, Aihara M (2018) Bird-egg syndrome induced by $\alpha$-livetin sensitization in a budgerigar keeper: Successful induction of tolerance by avoiding exposure to avians. Allergol Int. S1323-8930(18): 30160-30166.

6. Gomez Torrijos E, Garcia Rodriguez C, Rodriguez J (2015) Occupational asthma and eosinophilic esophagitis in a patient with egg-bird syndrome. J Investig Allergol Clin Immunol 25(1): 61-2.

7. Berbegal L, DeLeon FJ, González I (2017) Protein contact dermatitis caused by chicken meat in bird-egg syndrome. Contact Dermatitis 77(4): 253-254.

8. Hemmer W, Klug C, Swoboda I (2016) Update on the bird-egg syndrome and genuine poul-try meat allergy. Allergo J Int 25: 68-75.

9. Lou B, Xu Z, Yang G (2019) Role of Aspergillus fumigatus-Specific IgE in the Diagnosis of Allergic Bronchopulmonary Aspergillosis. Int Arch Allergy Immunol 9: 1-7.

10. Bartra Tomás J, Sáenz B from San Pedro Morera LA (2015) Navarro Seisdedos. Fungi as allergens Treaty of Allergology, $\left(2^{\text {nd }}\right.$ edn). Ergón 1: 275-286. 2015.

11. Parra Arrondo A, Lopez Rico R, Fraj Lazaro J (2015) Allergic bronchopulmonary aspergillosis. Treaty of Allergology, ( $2^{\text {nd }}$ ed). Ergón 2: 709-720. 


\section{ISSN: 2574-1241}

DOI: $10.26717 / B J S T R .2019 .13 .002461$

Vanesa García Paz. Biomed J Sci \& Tech Res

(C) (i) This work is licensed under Creative

Submission Link: https://biomedres.us/submit-manuscript.php

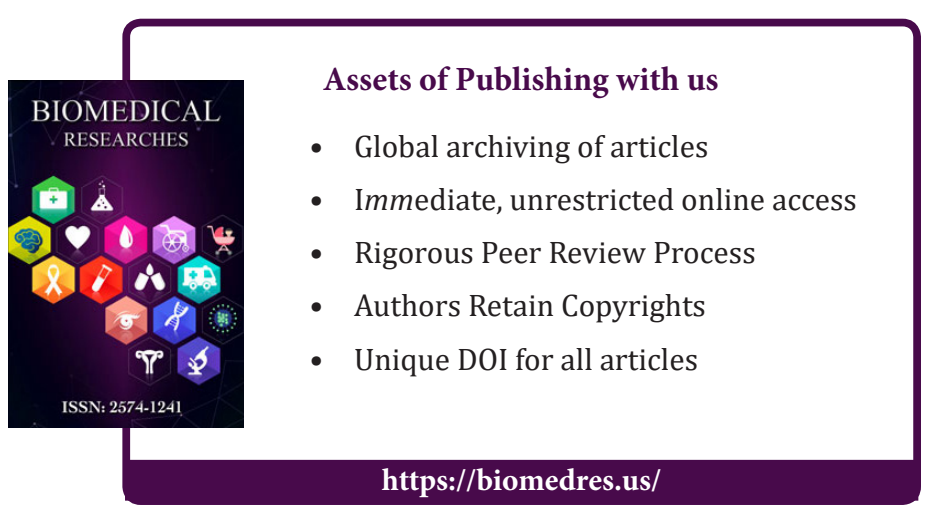

